\title{
REVIEW
}

\section{Clinical review: helmet and non-invasive mechanical ventilation in critically ill patients}

\author{
Antonio M Esquinas Rodriguez ${ }^{*}$, Peter J Papadakos², Michele Carron³, Roberto Cosentini ${ }^{4}$ and Davide Chiumello ${ }^{5}$
}

\begin{abstract}
Non-invasive mechanical ventilation (NIV) has proved to be an excellent technique in selected critically ill patients with different forms of acute respiratory failure. However, NIV can fail on account of the severity of the disease and technical problems, particularly at the interface. The helmet could be an alternative interface compared to face mask to improve NIV success. We performed a clinical review to investigate the main physiological and clinical studies assessing the efficacy and related issues of NIV delivered with a helmet. A computerized search strategy of MEDLINE/ PubMed (January 2000 to May 2012) and EMBASE (January 2000 to May 2012) was conducted limiting the search to retrospective, prospective, nonrandomized and randomized trials. We analyzed 152 studies from which 33 were selected, 12 physiological and 21 clinical (879 patients). The physiological studies showed that NIV with helmet could predispose to $\mathrm{CO}_{2}$ rebreathing and increase the patients'ventilator asynchrony. The main indications for NIV were acute cardiogenic pulmonary edema, hypoxemic acute respiratory failure (community-acquired pneumonia, postoperative and immunocompromised patients) and hypercapnic acute respiratory failure. In 9 of the 21 studies the helmet was compared to a face mask during either continous positive airway pressure or pressure support ventilation. In eight studies oxygenation was similar in the two groups, while the intubation rate was similar in four and lower in three studies for the helmet group compared to face mask group. The outcome was similar in six studies. The tolerance was better with the helmet in six of the studies. Although these data are limited, NIV delivered by helmet could be a safe alternative to the face mask in patients with acute respiratory failure.
\end{abstract}

*Correspondence: antmesquinas@gmail.com

IIntensive Care Unit, Hospital Morales Meseguer, Avenida Marques de Los Velez s/n, Murcia, 30008, Spain

Full list of author information is available at the end of the article
The standard treatment for acute respiratory failure in critically ill patients has been based on oxygen therapy and invasive mechanical ventilation with endotracheal intubation. In addition, non-invasive mechanical ventilation (NIV) has proved an excellent technique, avoiding the need for intubation and improving outcome in selected patients with acute cardiogenic pulmonary edema, exacerbation of chronic obstructive pulmonary disease (COPD), and acute hypoxemic respiratory failure [1-4]. Conversely to invasive mechanical ventilation, NIV can also be used outside the intensive care unit [5]. However, NIV can fail because of either the patient's underlying conditions or multiple technical causes. Despite improvements in the oro-nasal mask's characteristics, intolerance to the device represents a frequent cause of failure [6]; thus, the interface is fundamental in the care of patients. One possible alternative to the face mask could be the helmet, especially for long-term use (Figure 1). Although the facial mask is still the most commonly used interface in up to $60 \%$ of cases, in some European countries (such as Italy), the helmet is widely employed for patients with acute hypoxemic respiratory failure and acute cardiogenic pulmonary edema [6].

The aim of this clinical review is to summarize the main physiological and clinical studies assessing the efficacy (arterial oxygenation, intubation rate, outcome and tolerance) of NIV delivered with the helmet.

\section{Methods}

\section{Search strategy}

A computerized search of MEDLINE/PubMed (January 2000 to May 2012) and EMBASE (January 2000 to May 2012) for articles in English, Spanish and Italian was conducted, limiting the search to retrospective, prospective, non-randomized and randomized trials. The keywords 'noninvasive ventilation,' 'helmet' and 'interface' were combined with any of the terms 'chronic obstructive pulmonary disease,' 'hypoxemic acute respiratory failure', 'continuous positive airway pressure,' 'bi-level airway pressure' and 'pressure support ventilation'. The biographies of all selected articles were hand searched for additional relevant articles. 


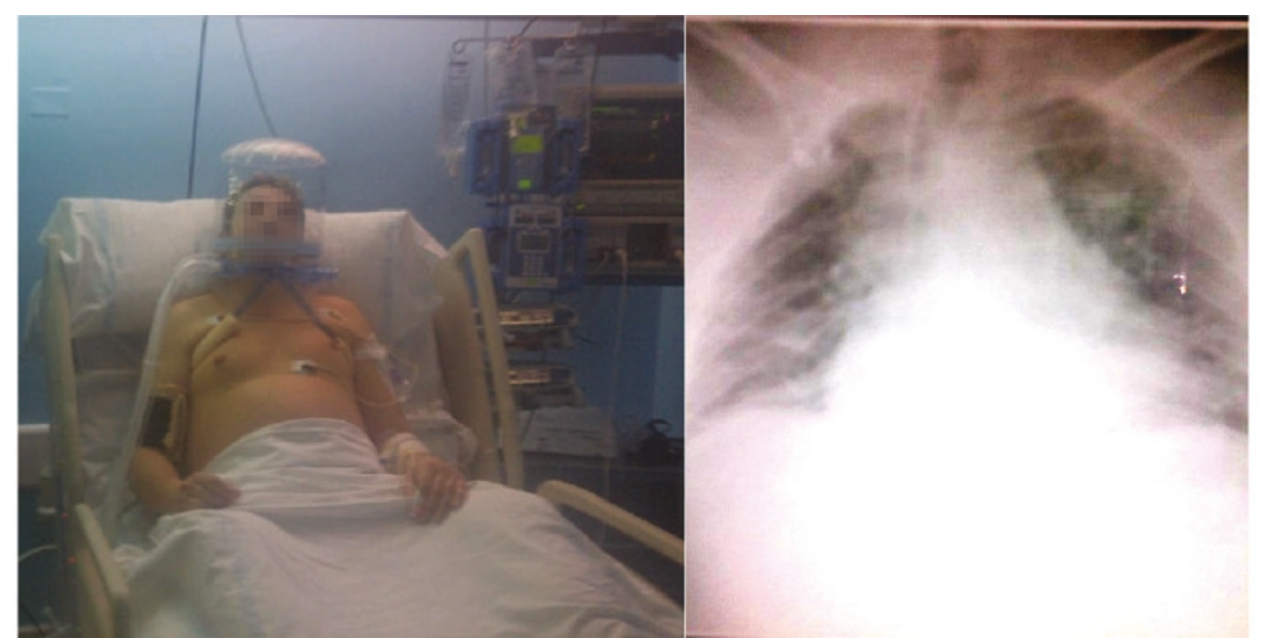

Figure 1. Non-invasive ventilation and helmet in use on a patient with acute respiratory syndrome in the ICU.

Five international experts participated and conducted this analysis (AE, PP, MC, RC, DC) and classified the results into two major groups: physiological and clinical studies.

\section{Results}

In the text the data are expressed as mean \pm standard deviation. We analyzed 152 studies from which 33 were selected for this clinical review. Twelve of these were physiological studies, performed in healthy subjects, and 21 were clinical studies, performed in patients with acute respiratory failure (Figure 2). Tables 1 and 2 summarize the main results.

\section{Physiological studies \\ Carbon dioxide rebreathing}

Compared to the face mask the helmet, due to its larger internal volume, might facilitate carbon dioxide $\left(\mathrm{CO}_{2}\right)$ rebreathing. Patroniti and colleagues [7] found that, with continuous flow continuous positive airway pressure (CPAP) and a gas flow from 20 to $60 \mathrm{~L} /$ minute and positive end-expiratory pressure (PEEP) from 0 to $15 \mathrm{cmH}_{2} \mathrm{O}$, the inspiratory $\mathrm{CO}_{2}$ concentration was always higher with the helmet than with the face mask ( $3.1 \pm 0.15$ versus $0.8 \pm 0.3 \mathrm{mmHg}, P<0.01)$. Increasing the gas flow rate significantly lowered the inspiratory $\mathrm{CO}_{2}$ concentration.

Similarly, Taccone and colleagues [8] observed that the $\mathrm{CO}_{2}$ concentration was similar between a continuous low flow CPAP (10 L/minute) and CPAP delivered by a mechanical ventilator $(13.7 \pm 6.6$ versus $12.4 \pm 3.2 \mathrm{mmHg})$. In addition, reducing the size of the helmet did not prevent $\mathrm{CO}_{2}$ rebreathing, suggesting that the $\mathrm{CO}_{2}$ rebreathing primarly depends on the fresh gas passing through the helmet and the amount of $\mathrm{CO}_{2}$ produced by the patient.

Among the commercially available helmets, $\mathrm{CO}_{2}$ rebreathing was lower than $5 \mathrm{mmHg}$ and not different during continuous high flow CPAP [9]. An antisuffocation valve, which allows room air to enter the helmet during any interruption of gas flow, limited the $\mathrm{CO}_{2}$ rebreathing but not the loss of external PEEP [9]. In a subsequent study, Milan and colleagues [10], testing three commercially available helmets supplied with antisuffocation valves, found that the helmet with the largest valve had lower $\mathrm{CO}_{2}$ rebreathing but a greater reduction in oxygenation in case of interruption of the gas flow.

Costa and colleagues [11] tested the helmet at different PSV and PEEP combinations and did not find any changes in $\mathrm{CO}_{2}$ rebreathing, which ranged from $5.2 \pm 3.1$ to $6.7 \pm 3.3 \mathrm{mmHg}$. However, during PSV of 5, 10 and $15 \mathrm{cmH}_{2} \mathrm{O}$ with an increased respiratory muscle load, the helmet was always associated with more $\mathrm{CO}_{2}$ rebreathing independent of the level of pressure support compared to the face mask $(4.3 \pm 0.5$ versus $0.0 \pm 0.0 \mathrm{mmHg}, 3.5 \pm 1.0$ versus $0.4 \pm 0.4 \mathrm{mmHg}$ and $4.4 \pm 1.3 \mathrm{mmHg}$ versus $0.5 \pm 0.6 \mathrm{mmHg} ; P<0.0001)$ [12].

Racca and colleagues [13] evaluated if an intentional leak at the helmet expiratory port during PSV, by increasing the flow through the helmet, could ameliorate the $\mathrm{CO}_{2}$ rebreathing. NIV and CPAP were delivered using closed and open circuit ventilators equipped with a plateau valve positioned at the helmet's expiratory port. $\mathrm{CO}_{2}$ rebreathing was significantly lower with the opencircuit ventilators. However, inspiratory pressure assistance significantly dropped with these open-circuit ventilators, casting doubt on the choice of the optimal helmet ventilation setup.

\section{Breathing pattern, inspiratory effort and comfort}

Besides the larger internal volume that affects $\mathrm{CO}_{2}$ rebreathing, the higher compliance of the helmet might delay ventilator assistance and may promote patientventilator asynchrony. 


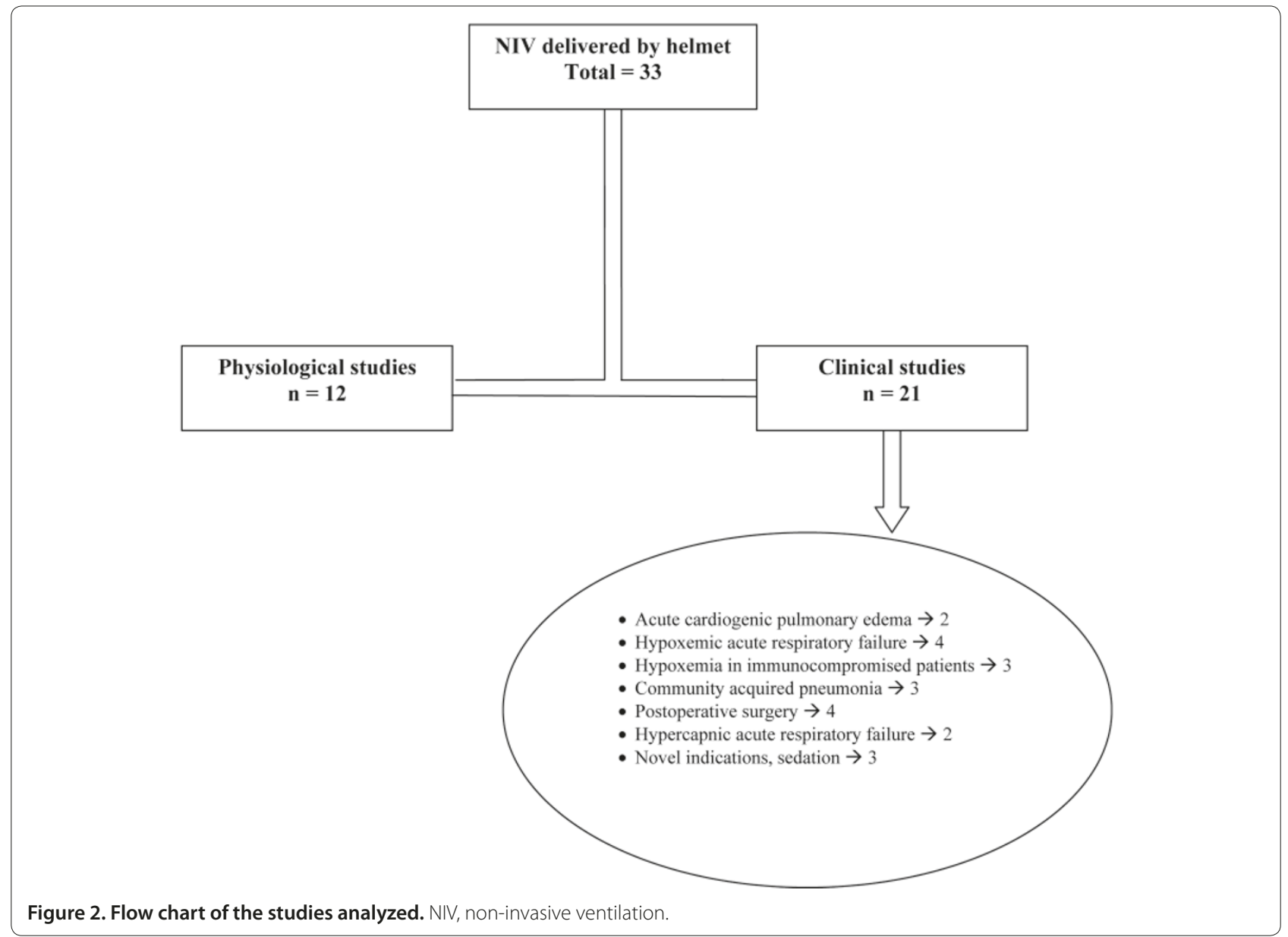

Chiumello and colleagues [14] evaluated the breathing pattern and work of breathing (WOB) with helmet and face masks during continuous flow CPAP, mechanical ventilator CPAP and PSV. During continuous flow CPAP, mechanical ventilator CPAP and PSV there was no difference in breathing pattern and WOB; on the contrary, during PSV the face mask significantly reduced the WOB compared to the helmet. The helmet requires a significant portion of the ventilator pressure in the initial phase of inspiration to pressurize its inner volume and not the patient, resulting in less assistance (that is, it takes a longer time to reach the required level of pressure support).

In a subsequent study Costa and colleagues [11], raising the level of pressure support from 5 to $15 \mathrm{cmH}_{2} \mathrm{O}$, found that the respiratory rate and inspiratory effort with the helmet progressively decreased and tidal volume increased compared to spontaneous breathing. The highest level of pressure support $\left(15 \mathrm{cmH}_{2} \mathrm{O}\right)$ significantly increased the discomfort.

Racca and colleagues [12] compared the helmet and face mask during PSV with normal and high respiratory muscle load to mimic dyspneic patients. With normal muscle load the breathing pattern and inspiratory effort was not different with helmet and face mask, but with high respiratory muscle load the inspiratory effort was significantly higher with the helmet than with the face mask.

Helmet devices may predispose to auto-cycled phenomena. Its elastic properties thus predispose to flow variations not tracked by effective inspiratory or expiratory efforts. Autocycled breathing was more common with helmet ventilation - on average double that with face mask ventilation [12]. The dyspnea score was significantly higher with high respiratory muscle load with helmet compared to face mask ventilation [12].

\section{Patient ventilator synchrony}

PSV, the most commonly used ventilatory support during NIV, is regulated by pneumatic triggering based on flow criteria. To improve patient ventilator synchrony, it is possible in most current mechanical ventilators to adjust the pressurization time and the expiratory cycling off criteria to better match the neural time with the ventilator time [15-18]. Costa and colleagues [19] examined the effects of different pressurization times and different 
Table 1. Summary of the physiological studies

\begin{tabular}{|c|c|c|c|c|c|}
\hline Source & $\begin{array}{l}\text { Type of } \\
\text { non-invasive } \\
\text { ventilation }\end{array}$ & $\begin{array}{c}\text { Number } \\
\text { of subjects }\end{array}$ & Interface & Control & Results \\
\hline Patroniti et al. (2003) [7] & CPAP & 8 & Helmet & FM & Higher $\mathrm{CO}_{2}$ rebreathing with helmet \\
\hline Taccone et al. (2004) [8] & CPAP & 8 & Helmet & FM & Higher $\mathrm{CO}_{2}$ rebreathing with helmet \\
\hline Patroniti et al. (2007) [9] & CPAP & 5 & $\begin{array}{l}\text { Helmet with } \\
\text { and without } \\
\text { antisuffocation valve }\end{array}$ & - & $\mathrm{CO}_{2}$ rebreathing limited by safety valve \\
\hline Milan et al. (2011) [10] & CPAP & 5 & $\begin{array}{l}\text { Helmet with } \\
\text { antisuffocation valve }\end{array}$ & - & $\begin{array}{l}\mathrm{CO}_{2} \text { rebreathing decreased by a higher } \\
\text { diameter of safety valve }\end{array}$ \\
\hline Costa et al. (2005) [11] & PSV & 8 & Helmet & - & $\begin{array}{l}\mathrm{CO}_{2} \text { rebreathing not affected by } \\
\text { PEEP on PSV level; inspiratory effort } \\
\text { decreased, increasing the PSV }\end{array}$ \\
\hline Racca et al. (2008) [13] & PSV - CPAP & 10 & Helmet & - & $\begin{array}{l}\text { Lower } \mathrm{CO}_{2} \text { rebreathing with open } \\
\text { circuit mechanical ventilators }\end{array}$ \\
\hline Chiumello et al. (2003) [14] & PSV - CPAP & 6 & Helmet & FM & $\begin{array}{l}\text { Similar breathing pattern and WOB } \\
\text { during CPAP, higher reduction of WOB } \\
\text { during PSV with FM }\end{array}$ \\
\hline Racca et al. (2005) [12] & PSV & 6 & Helmet & FM & $\begin{array}{l}\text { Higher } \mathrm{CO}_{2} \text { rebreathing, inspiratory } \\
\text { effort, autocycled breaths and } \\
\text { dyspnea score with helmet during } \\
\text { respiratory muscle load }\end{array}$ \\
\hline Costa et al. (2010) [19] & $\begin{array}{l}\text { PSV different } \\
\text { inspiratory-expiratory } \\
\text { cycling criteria }\end{array}$ & 8 & Helmet & FM & $\begin{array}{l}\text { Shorter ventilator inspiratory time } \\
\text { and longer with inspiratory-expiratory } \\
\text { delay with helmet. The fast setting } \\
\text { ameliorated patient-ventilator } \\
\text { interaction }\end{array}$ \\
\hline Moerer et al. (2008) [21] & $\begin{array}{l}\text { PSV pneumatically } \\
\text { versus neurally } \\
\text { triggered }\end{array}$ & 7 & Helmet & - & $\begin{array}{l}\text { Shorter inspiratory-expiratory delays, } \\
\text { lower wasted efforts and better } \\
\text { comfort with neurally triggered PSV }\end{array}$ \\
\hline Chiumello et al. (2008) [24] & CPAP & 10 & Helmet & - & $\begin{array}{l}\text { Higher temperature and humidity } \\
\text { of inspired gas compared to un- } \\
\text { humidified medical gases }\end{array}$ \\
\hline Cavaliere et al. (2003) [25] & PSV & 10 & Helmet & $\mathrm{FM}$ & $\begin{array}{l}\text { Higher acoustic compliance with } \\
\text { helmet }\end{array}$ \\
\hline
\end{tabular}

$\mathrm{CO}_{2}$, carbon dioxide; $\mathrm{CPAP}$, continuous positive airway pressure; $\mathrm{FM}$, face mask; $\mathrm{PSV}$, pressure-support ventilation; WOB, work of breathing.

expiratory cycling criteria during PSV delivered by helmet or face mask. The ventilator inspiratory time was significantly longer with the face mask compared to the helmet. The helmet presented a significantly longer inspiratory and shorter expiratory trigger delay. However, a shorter pressurization time compared to a longer or intermediate time resulted in a significant improvement in patient ventilator synchrony.

To ameliorate the asynchrony that can be present with conventional pneumatic ventilator triggering, neural triggering using diaphragm electrical activity has been developed [20]. Moerer and colleagues [21] compared neurally and pneumatically triggered PSV delivered with a helmet with regard to synchrony and patient comfort. The pneumatic trigger was delayed compared to the neural trigger and directly increased with the level of PSV; during pneumatic triggering the number of wasted efforts increased with high PSV, while wasted inspiratory efforts did not occur during neural triggering. The expiratory delay was always lower with pneumatic compared to neural triggering. Comfort of breathing was also lower during pneumatic triggering compared to neural triggering.

\section{Humidity and noise}

Although the optimal level of humidification of inspired gases during NIV is unknown, inadequate humidification can cause patient distress and favour intolerance $[1,22$, 23]. Similar to $\mathrm{CO}_{2}$ rebreathing related to the helmet's high internal volume, the humidity of expired gases can 


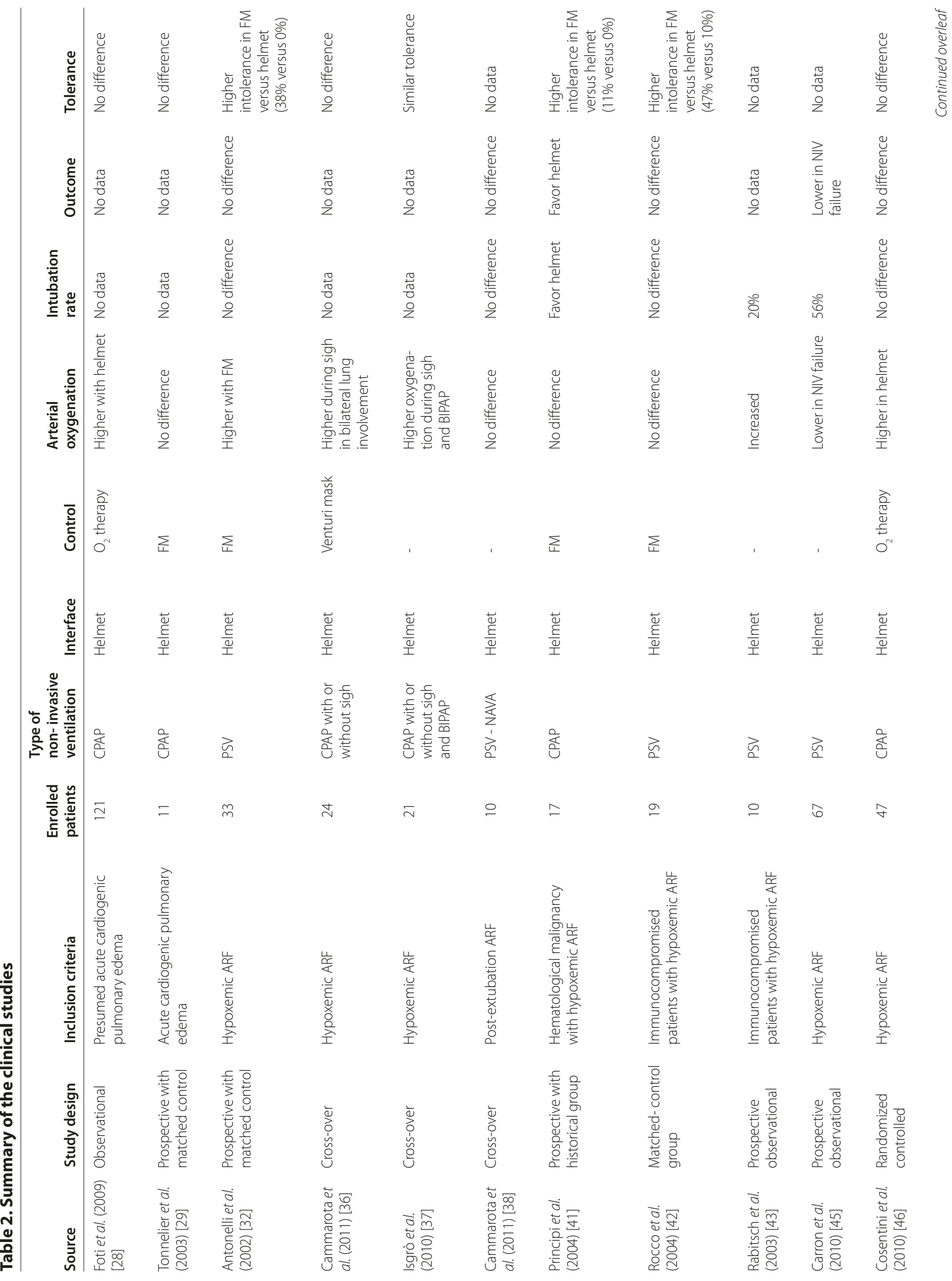




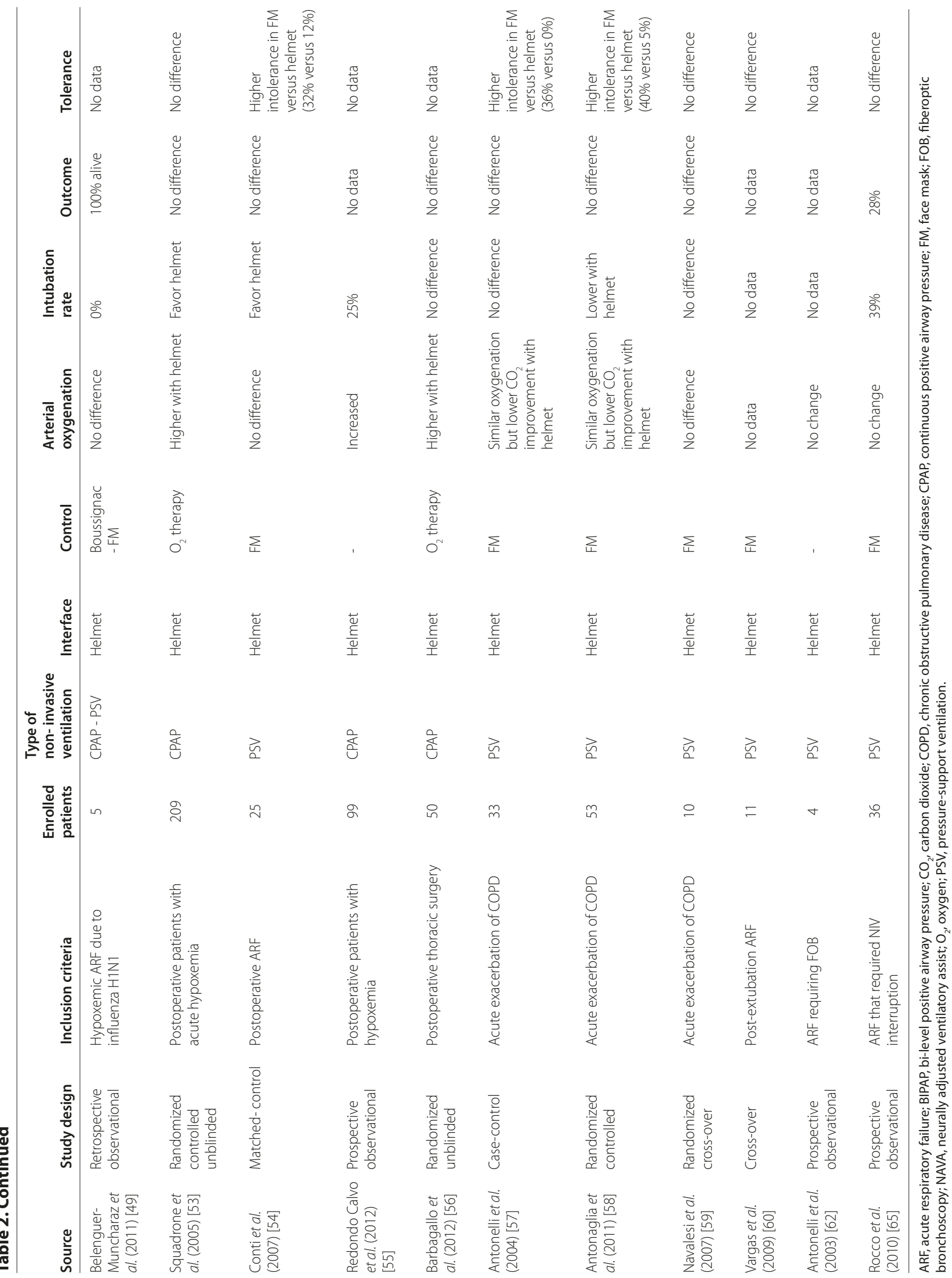


mix with the fresh inspired gases, which are more dry and cold, thus increasing the level of heat and humidity, avoiding the necessity of active humidification. Chiumello and colleagues [24] reported that during continuous flow CPAP without an active humidifier, the temperature and humidity levels of the inspired gases were significantly higher compared to non-humidified medical gases and they were directly dependent on the gas flow passing throught the helmet.

Compared to the face mask the helmet can expose the entire head to positive pressure, which may injure the tympanic membranes. Cavaliere and colleagues [25] evaluated the performance of the middle ear by recording the tympanometry and the acoustic reflex after one hour of PSV with both the helmet and the face mask. During PSV with the helmet, the tympanometry showed a slight increase in acoustic compliance but returned to basal values after one hour, while it did not show a change with the face mask. In both groups the acoustic reflex did not change. These data may suggest the use of ear plugs in selective cases, such as during long-term use and when high airway pressures are used.

\section{Clinical studies \\ Acute cardiogenic pulmonary edema}

During acute pulmonary edema the main beneficial effects of NIV besides the improvement of gas exhange are the reduction of preload and afterload, which improves the cardiac performace $[26,27]$.

In an observational study of 121 patients with presumed acute pulmonary cardiogenic edema, Foti and colleagues [28], in a prehospital setting applying a continous flow CPAP with a helmet, found a significant improvement in arterial oxygen saturation $(79 \pm 12 \%$ versus $97 \pm 3 \%, P<0.01$ ) and in hemodynamics (systolic blood pressure $175 \pm 49 \mathrm{mmHg}$ versus $145 \pm 28 \mathrm{mmHg}$, $P<0.01)$. The helmet CPAP was well tolerated in all enrolled patients.

In a prospective pilot study with a matched control group of patients with hypoxemic acute respiratory failure related to cardiogenic pulmonary edema, Tonnelier and colleagues [29] reported that helmet CPAP significantly reduced respiratory rate and heart rate and improved oxygenation $(158 \quad \pm 94 \mathrm{mmHg}$ versus $145 \pm 28 \mathrm{mmHg}$ ), similar to the mask. Control patients were selected from a group of patients with acute respiratory failure due to cardiogenic pulmonary edema treated with a facial mask. The helmet allowed a longer period of CPAP without any adverse event and good tolerance.

\section{Hypoxemic acute respiratory failure}

In a large multicenter survey of patients with hypoxemic acute respiratory failure, NIV was successful in avoiding intubation in $70 \%$ of the patients [30]. Patients with a high severity score (simplified acute physiology score (SAPS) II >34), older age, acute respiratory distress syndrome or pneumonia, severe metabolic acidosis, severe hypoxemia (partial pressure of oxygen in arterial blood $\left(\mathrm{PaO}_{2}\right)$ /fraction of inspired oxygen $\left.\left(\mathrm{FiO}_{2}\right)<170\right)$ or failure in improvement in $\mathrm{PaO}_{2} / \mathrm{FiO}_{2}$ after one hour of treatment were at higher risk of failure [31].

In a matched control study, Antonelli and colleagues [32] evaluated the efficiency of PSV delivered by helmet or face mask in patients with hypoxemic acute respiratory failure. Both groups had a similar improvement in oxygenation within the first hour; however, at support discontinuation the increase in oxygenation was higher for patients who received PSV by helmet $(267 \pm 104 \mathrm{mmHg}$ versus $224 \pm 81 \mathrm{mmHg}, P<0.05)$. The total duration of PSV was similar ( $40 \pm 30$ hours versus $42 \pm 31$ hours), as well as the intubation rate and hospital mortality. No patients in the helmet group compared to $38 \%$ of the mask group had intolerance to NIV.

The application of periodic deep insufflation (sighs) during invasive mechanical ventilation may improve gas exchange [33-35]. In a prospective cross-over study, Cammarota and colleagues [36] found that during CPAP with either the helmet or face mask, the sigh (that is, an increase of airway pressure from 10 to $20 \mathrm{cmH}_{2} \mathrm{O}$ for 8 seconds every minute) significantly improved the arterial oxygenation and reduced the respiratory rate. Independent of sigh, the helmet CPAP group had higher oxygenation while the tolerance was similar in the two groups.

Similarly to the previous study [36], in hypoxemic acute respiratory failure Isgrò and colleagues [37], applying a periodic sigh or two CPAP levels (similar to bi-level positive airway pressure (BIPAP) ventilation) during continuous flow CPAP with a helmet, found a significant improvement in oxygenation compared to basal CPAP $(109.2 \pm 33.9 \mathrm{mmHg}$ versus $124.5 \pm 45.2 \mathrm{mmHg}$ and $128 \pm 52 \mathrm{mmHg}$ ). There was no significant difference between sigh and BIPAP regarding oxygenation levels.

Compared to PSV, neurally adjusted ventilatory assist (NAVA) improved ventilator synchrony in healthy subjects [21]. Cammarota and colleagues [38] evaluated the short-term physiologic effects of NAVA compared to PSV delivered with helmet in postextubation acute respiratory failure. NAVA significantly increased the ventilator inspiratory and reduced expiratory time. No asynchrony was present with NAVA, while there were no differences in gas exchange and respiratory rate.

\section{Immunocompromised patients}

The respiratory complications in immuncompromised patients remain the main cause of morbidity and mortality; thus, respiratory support that avoids or reduces pulmonary complications could be useful $[39,40]$. 
Principi and colleagues [41], in a prospective clinical study of hematological malignancy patients with hypoxemic acute respiratory failure compared to historical matched controls, observed that no patient failed helmet CPAP due to intolerance of the technique compared to $11.4 \%$ of patients in the mask group, and that helmet CPAP could be applied continuously over a much longer period of time than mask CPAP $(28.4 \pm 0.2$ hours versus $7.5 \pm 0.4$ hours, $P<0.001$ ). The oxygenation improvement was equal in the two groups but the intubation and mortality rates were lower with the helmet $(0$ versus $41 \%$ and 23 versus $47 \%, P<0.001$ ).

Rocco and colleagues [42], in a matched controlled study of immunocompromised patients of different etiologies of acute respiratory failure, showed that patients receiving PSV with helmet had significantly lower NIV discontinuations in the first 24 hours than patients treated with mask; also, fewer complications related to device were reported (that is, skin necrosis, $P=0.01$ ). Oxygenation, intubation and mortality rates were similar $(202 \pm 61 \mathrm{mmHg}$ versus $224 \pm 111 \mathrm{mmHg}, 37 \%$ versus $47 \%$, and $47 \%$ versus $31 \%$, respectively).

In an observational study of immunocompromised patients with acute respiratory failure, Rabitsch and colleagues [43] reported that helmet PSV significantly improved arterial oxygenation and respiratory rate, and only two patients $(20 \%)$ were intubated.

\section{Community-acquired pneumonia}

Severe community-aquired pneumonia with intensive care admission and associated hypoxemic acute respiratory failure can require respiratory support in up of $60 \%$ of patients [44]. Carron and colleagues [45], in a prospective observational study including 64 consecutive patients with acute respiratory failure due to communityaquired pneumonia, investigated the failure of NIV. NIV was delivered as PSV with helmet. It was found that NIV succeeded in $43 \%$ of patients and failed in $56 \%$. The only two independent factors associated with failure were changes in arterial oxygenation and oxygenation index between admission and after 1 hour of NIV.

In a large multicenter randomized controlled trial in patients with hypoxemic acute respiratory failure due to community-aquired pneumonia, Cosentini and colleagues [46] compared continuous flow CPAP delivered by helmet and oxygen therapy for improving oxygenation. The primary end point was the time required to reach a $\mathrm{PaO}_{2} / \mathrm{FiO}_{2}$ ratio above $315 \mathrm{mmHg}$. This was reached in a significantly shorter time in the helmet group compared to the control group (1.5 hours versus 48 hours, $P<0.001)$. In the helmet group $95 \%$ of patients reached this end point compared to $30 \%$ of the controls $(P<0.001)$. No patients required intubation or died during the study.
In the last recent pandemic due to influenza A (H1N1) it was reported that patients admitted to intensive care for acute respiratory failure with severe hypoxemia required respiratory support in up of $80 \%$ of cases $[47,48]$. A retrospective observational study evaluated the use of NIV in all patients admitted to intensive care with presumed or confirmed influenza A (H1N1) infection and hypoxemic acute respiratory failure [49]. NIV was delivered as CPAP and PSV with a helmet or face mask. There was a significant improvement in gas exchange and respiratory and heart rates decreased. None of the patients required orotracheal intubation (100\% success) and all the patients survived.

\section{Postoperative surgery}

Postoperative complications, which include atelectasis, pulmonary edema, postoperative pneumonia and acute respiratory failure, arise in $5 \%$ to $10 \%$ of all surgical patients and significantly increase morbidity and mortality [1,50-52].

In a randomized, controlled, unblinded study, Squadrone and colleagues [53] showed that postoperative patients who developed hypoxemia and received helmet CPAP compared to those treated with oxygen alone had a better oxygenation and a lower intubation rate $(1 \%$ versus $10 \%$, $P=0.005)$. The helmet group had a lower rate of pneumonia ( $2 \%$ versus $10 \%, P=0.02)$, infection $(3 \%$ versus $10 \%, P=0.03$ ), and sepsis ( $2 \%$ versus $9 \%, P=0.03$ ), and spent fewer days in the ICU $(1.4 \pm 1.6$ versus $2.6 \pm 4.2, P=0.09)$ without any difference in the hospital length of stay $(15 \pm 13$ versus $17 \pm 15, P=0.10)$.

In a matched-control study, Conti and colleagues [54] also found that in patients with acute respiratory failure after major abdominal surgery, PSV delivered by a helmet significantly improved oxygenation and reduced intubation rate (20\% versus $48 \%, P=0.036)$ compared to PSV with facial mask. The complications (mask intolerance, major leaks and ventilator-associated pneumonia) were significantly lower in the helmet group compared to the face mask group ( $12 \%$ versus $32 \%, P=0.06$ ).

In a prospective observational study evaluating helmet CPAP in postoperative patients who developed acute hypoxemic respiratory failure, Redondo-Calvo [55] and colleagues found that $74.7 \%$ of the patients did not require intubation. The intubated patients presented higher levels of illness and lower improvement in oxygenation and CPAP duration. The intubated patients had a longer hospital stay and higher rate of hospital deaths compared to unintubated $(30.2 \pm 20.1$ days versus $12.7 \pm 8.2$ days, $P<0.001$, and $44 \%$ versus $15 \%, P=0.004$ ).

Although the NIV is commonly used to treat acute respiratory failure in postoperative patients, it has also been used to prevent acute respiratory complications after surgery [50]. Barbagallo and colleagues [56] 
randomized 50 patients after elective lung resection to a prophylactic continuous flow CPAP with helmet for two hours or to oxygen therapy. The helmet group had significantly higher oxygenation without any difference in postoperative complications and mortality.

\section{Hypercapnic acute respiratory failure}

In COPD patients, NIV is recommended to improve gas exchange, and to decrease respiratory workload and the need for tracheal intubation $[1,4]$.

In a cohort study, Antonelli and colleagues [57] evaluated the effect of PSV delivered by helmet or by face mask on gas exchange and intubation rate in COPD patients with acute exacerbation. After one hour both groups presented a significant reduction of partial pressure of carbon dioxide in arterial blood $\left(\mathrm{PaCO}_{2}\right)$ and improvement in $\mathrm{pH}$. However, the decrease in $\mathrm{PaCO}_{2}$ was lower in the helmet group compared to the face mask group (75 $\pm 15 \mathrm{mmHg}$ versus $66 \pm 15 \mathrm{mmHg}, P=0.01$ ). Also, on discontinuing support, $\mathrm{PaCO}_{2}$ was higher $(P=0.002)$ and $\mathrm{pH}$ lower $(P=0.02)$ in the helmet group. The improvements in oxygenation and respiratory rate were similar as well as the intubation rate (30\% versus $42 \%)$. Intensive care and hospital mortality were not different between the groups.

Antonaglia and colleagues [58] ventilated a series of patients with severe exacerbation of COPD using PSV delivered by face mask for two hours; subsequently, only those in whom gas exchange improved were randomized to helmet or face mask. After four hours of NIV, the face mask group had a significantly lower $\mathrm{PaCO}_{2}$ compared to the helmet group $(63 \pm 14 \mathrm{mmHg}$ versus $70 \pm 4 \mathrm{mmHg}$, $P=0.01)$ with no difference in oxygenation or respiratory rate. However, 9 of the 20 patients (45\%) in the mask group compared to 2 of $20(5 \%)$ in the helmet group required intubation $(P<0.01)$.

In a small group of hypercapnic patients with severe COPD recovering from acute exacerbation, Navalesi and colleagues [59] evaluated PSV delivered by a helmet or face mask in random order. Compared to spontaneous breathing, NIV reduced $\mathrm{PaCO}_{2}$ with both devices (from $55.9 \pm 7.3 \mathrm{mmHg}$ to $52.0 \pm 7.1 \mathrm{mmHg}$ with helmet, $P<0.05$; and from $55.5 \pm 7.7 \mathrm{mmHg}$ to $51.7 \pm 8.5 \mathrm{mmHg}$ with face mask, $P<0.05)$. Ineffective inspiratory efforts were significantly more common with the helmet and although the WOB decreased to a similar extent as for spontaneous breathing, with the helmet the delay between inspiratory effort and ventilator support was significantly longer.

\section{Interfaces}

In a prospective cross-over study Vargas and colleagues [60], in a group of patients at high risk for respiratory distress, compared three different NIV settings: PSV delivered by face mask; PSV at the same pressure support and PEEP with helmet; and PSV with 50\% increases in pressure support and PEEP with helmet. At the same level of pressure support the helmet had a low inspiratory effort compared to face mask. The increase of PSV reduced the inspiratory effort to a similar extent as with the face mask. Patient ventilator asynchrony was more frequent with the helmet, while respiratory rate and patient comfort were similar among the three conditions.

\section{Novel indications}

Arterial oxygenation lower than $75 \mathrm{mmHg}$ with an oxygen fraction higher than $50 \%$ is considered a contraindication to fiberoptic bronchoscopy [61]. Antonelli and colleagues [62] investigated the feasibility and safety of fiberoptic bronchoscopy with bronchoalveolar lavage during NIV delivered with a helmet in patients with acute respiratory failure. Oxygenation did not change throughout the procedure and dropped only $2 \%$ at the end of the fiberoptic bronchoscopy. No patients required sedatives or analgesics.

\section{Sedation}

Similar to invasive mechanical ventilation, sedation has been advocated to improve NIV tolerance and reduce the rate of failure [63,64].

In a prospectively uncontrolled study, Rocco and colleagues [65] evaluated the continuous infusion of remifentanil in patients with hypoxemic acute respiratory failure during NIV with helmet or mask. The mean remifentanil dose administered was $0.07 \pm 0.03 \mu \mathrm{g} / \mathrm{kg} /$ minute and infusion lasted $52 \pm 10$ hours in the success group. Thirty-six patients were enrolled and 22 (61\%) continued NIV treatment; after one hour respiratory rate decreased and oxygenation increased with both helmet and face mask. Fourteen patients failed (39\%) and required endotracheal intubation because of persistence of discomfort.

\section{Discussion}

In this review we identified, among the 33 studies considered, only 9 clinical studies in which the helmet was compared to face mask. The helmet presented similar oxygenation rates in eight [29,41,42,49,54,57-59] and similar intubation rates in four $[32,42,57,59]$ of these compared to the face mask. The outcome was similar in six studies [32,42,54,57-59]. The tolerance was better with helmet in six of these studies [58,32,57,54,41,42].

The main application of NIV with helmet was for acute cardiogenic pulmonary edema, hypoxemic acute respiratory failure, community-acquired pneumonia, hypercapnic acute respiratory failure, and in post-operative and immunocompromised patients. The main favourable characteristics of the helmet (Table 3), such as low 
Table 3. Major advantages and disvantages of the helmet

\begin{tabular}{ll}
\hline Advantages & Disadvantages \\
\hline Nutrition and hydration & Noise \\
Lower air leaks & Large dead space \\
No facial skin lesions & Claustrophobia \\
No eye irritation & Vascular complications \\
Independent of the patient's & Skin lesions at the collar neck \\
anatomy & Desyncrhonization between patient \\
& and ventilator \\
\hline
\end{tabular}

Table 4. Suggested key points for non-invasive ventilation delivered by helmet

General recommendations

Use helmet in case of long duration non-invasive ventilation

Use helmet in case of face skin lesions

Use helmet in case of major air leaks

Use helmet in edentulous patients

Use helmet if mask intolerance

Avoid CPAP delivered by mechanical ventilator

Promote inter-change between helmet and face mask during long treatment

Frequent assessment of gas exchange in the first hours

Continuous flow CPAP

Use inspiratory gas flow $>40 \mathrm{~L} /$ minute

Pressure-support ventilation

Apply higher PEEP and pressure support level (50\% higher than those applied with face mask)

Use the maximum pressurization rate

CPAP, continuous positive airway pressure; PEEP, positive end-expiratory pressure.

distensibility, absence of any contact with the face, minimum presence of air leaks, the possibility to deliver continous flow CPAP as well as non-invasive positive pressure ventilation, can extend the application of NIV in patients with acute respiratory failure. However, the high internal volume can promote higher $\mathrm{CO}_{2}$ rebreathing, patient ventilator asynchrony and lower reductions in WOB compared to the face mask. Higher levels of pressure support and faster pressurization rates, however, could improve the efficiency of the helmet to be comparable to the face mask. Table 4 summarizes general recommendations to optimize NIV with the helmet.

\section{Conclusion}

The helmet has been shown to be an effective interface for the application of NIV, but compared to the face mask it may increase patient ventilator asynchrony and $\mathrm{CO}_{2}$ rebreathing. However, the helmet is better tolerated, allowing longer use. Further studies are required to define the ideal patient populations and open up new clinical indications for NIV with the helmet.

\section{Abbreviations}

BIPAP, bi-level positive airway pressure; COPD, chronic obstructive pulmonary disease; $\mathrm{CPAP}$, continuous positive airway pressure; $\mathrm{FiO}_{2}$, fraction of inspired oxygen; NAVA, neurally adjusted ventilatory assist; NIV, non-invasive ventilation; $\mathrm{PaCO}_{2^{\prime}}$ partial pressure of carbon dioxide in arterial blood; $\mathrm{PaO}_{2^{\prime}}$ partial pressure of oxygen in arterial blood; PEEP, positive end-expiratory pressure; PSV, pressure-support ventilation; WOB, work of breathing.

\section{Competing interests}

The authors declare that they have no competing interests.

\section{Acknowledgements}

Written consent to publish was received from the patient in Figure 1.

\section{Author details}

'Intensive Care Unit, Hospital Morales Meseguer, Avenida Marques de Los Velez s/n, Murcia, 30008, Spain. '2University of Rochester, Rochester, NY 14642, USA. ${ }^{3}$ Department of Medicine, Anesthesiology and Intensive Care, University of Padova, 35121 Padova, Italy. ${ }^{4}$ Gruppo NIMV UO Medicina d'Urgenza, Fondazione IRCCS Ca' Granda, Ospedale Maggiore Policlinico, 20122 Milano, Italy. ${ }^{5}$ Anestesia, Rianimazione e Terapia del dolore, Fondazione IRCCS Ca' Granda - Ospedale Maggiore Policlinico, 20145 Milano, Italy.

Published: 25 April 2013

\section{References}

1. International Consensus Conferences in Intensive Care Medicine: noninvasive positive pressure ventilation in acute Respiratory failure. Am J Respir Crit Care Med 2001, 163:283-291.

2. Hill NS, Brennan J, Garpestad E, Nava S: Noninvasive ventilation in acute respiratory failure. Crit Care Med 2007, 35:2402-2407.

3. Crimi C, Noto A, Princi P, Nava S: Survey of non-invasive ventilation practices: a snapshot of Italian practice. Minerva Anestesiol 2011, 77:971-978.

4. Ferreyra G, Fanelli V, Del Sorbo L, Ranieri VM: Are guidelines for non-invasive ventilation during weaning still valid? Minerva Anestesiol 2011, 77:921-926.

5. Cabrini L, Antonelli M, Savoia G, Landriscina M: Non-invasive ventilation outside of the Intensive Care Unit: an Italian survey. Minerva Anestesiol 2011, 77:313-322.

6. Crimi C, Noto A, Princi P, Esquinas A, Nava S: A European survey of noninvasive ventilation practices. Eur Respir J 2010, 36:362-369.

7. Patroniti N, Foti G, Manfio A, Coppo A, Bellani G, Pesenti A: Head helmet versus face mask for non-invasive continuous positive airway pressure: a physiological study. Intensive Care Med 2003, 29:1680-1687.

8. Taccone P, Hess D, Caironi P, Bigatello LM: Continuous positive airway pressure delivered with a "helmet": effects on carbon dioxide rebreathing. Crit Care Med 2004, 32:2090-2096.

9. Patroniti N, Saini M, Zanella A, Isgro S, Pesenti A: Danger of helmet continuous positive airway pressure during failure of fresh gas source supply. Intensive Care Med 2007, 33:153-157.

10. Milan M, Zanella A, Isgro S, Deab SA, Magni F, Pesenti A, Patroniti N: Performance of different continuous positive airway pressure helmets equipped with safety valves during failure of fresh gas supply. Intensive Care Med 2011, 37:1031-1035.

11. Costa R, Navalesi P, Antonelli M, Cavaliere F, Craba A, Proietti R, Conti G: Physiologic evaluation of different levels of assistance during noninvasive ventilation delivered through a helmet. Chest 2005, 128:2984-2990.

12. Racca F, Appendini L, Gregoretti C, Stra E, Patessio A, Donner CF, Ranieri VM: Effectiveness of mask and helmet interfaces to deliver noninvasive ventilation in a human model of resistive breathing. J App/ Physio/ 2005, 99:1262-1271.

13. Racca F, Appendini L, Gregoretti C, Varese I, Berta G, Vittone F, Ferreyra G, Stra E, Ranieri VM: Helmet ventilation and carbon dioxide rebreathing: effects of adding a leak at the helmet ports. Intensive Care Med 2008, 34:1461-1468.

14. Chiumello D, Pelosi P, Carlesso E, Severgnini P, Aspesi M, Gamberoni C, Antonelli M, Conti G, Chiaranda M, Gattinoni L: Noninvasive positive pressure ventilation delivered by helmet vs. standard face mask. Intensive Care Med 2003, 29:1671-1679.

15. Chiumello D, Pelosi P, Taccone P, Slutsky A, Gattinoni L: Effect of different inspiratory rise time and cycling off criteria during pressure support ventilation in patients recovering from acute lung injury. Crit Care Med 
2003, 31:2604-2610

16. Chiumello D, Polli F, Tallarini F, Chierichetti M, Motta G, Azzari S, Colombo R, Rech R, Pelosi P, Raimondi F, Gattinoni L: Effect of different cycling-off criteria and positive end-expiratory pressure during pressure support ventilation in patients with chronic obstructive pulmonary disease. Crit Care Med 2007, 35:2547-2552.

17. Tassaux D, Gainnier M, Battisti A, Jolliet P: Impact of expiratory trigger setting on delayed cycling and inspiratory muscle workload. Am J Respir Crit Care Med 2005, 172:1283-1289.

18. Yamada Y, Du HL: Analysis of the mechanisms of expiratory asynchrony in pressure support ventilation: a mathematical approach. J App/ Physio/ 2000, $88: 2143-2150$

19. Costa R, Navalesi P, Spinazzola G, Ferrone G, Pellegrini A, Cavaliere F, Proietti R, Antonelli M, Conti G: Influence of ventilator settings on patient-ventilator synchrony during pressure support ventilation with different interfaces. Intensive Care Med 2010, 36:1363-1370.

20. Sinderby C, Navalesi P, Beck J, Skrobik Y, Comtois N, Friberg S, Gottfried SB, Lindstrom L: Neural control of mechanical ventilation in respiratory failure. Nat Med 1999, 5:1433-1436

21. Moerer O, Beck J, Brander L, Costa R, Quintel M, Slutsky AS, Brunet F, Sinderby $C$ : Subject-ventilator synchrony during neural versus pneumatically triggered non-invasive helmet ventilation. Intensive Care Med 2008, 34:1615-1623.

22. Esquinas Rodriguez AM, Scala R, Soroksky A, Bahammam A, de Klerk A, Valipour A, Chiumello D, Martin C, Holland AE: Clinical review: Humidifiers during non-invasive ventilation - key topics and practical implications. Crit Care 2012, 16:203.

23. Gross JL, Park GR: Humidification of inspired gases during mechanical ventilation. Minerva Anestesio/ 2012, 78:496-502

24. Chiumello D, Chierichetti M, Tallarini F, Cozzi P, Cressoni M, Polli F, Colombo R, Castelli A, Gattinoni L: Effect of a heated humidifier during continuous positive airway pressure delivered by a helmet. Crit Care 2008, 12:R55.

25. Cavaliere F, Masieri S, Conti G, Antonelli M, Pennisi MA, Filipo R, Proietti R: Effects of non-invasive ventilation on middle ear function in healthy volunteers. Intensive Care Med 2003, 29:611-614.

26. Ambrosino N, Vagheggini G: Noninvasive positive pressure ventilation in the acute care setting: where are we? Eur Respir J 2008, 31:874-886.

27. Masip J, Roque M, Sanchez B, Fernandez R, Subirana M, Exposito JA: Noninvasive ventilation in acute cardiogenic pulmonary edema: systematic review and meta-analysis. JAMA 2005, 294:3124-3130.

28. Foti G, Sangalli F, Berra L, Sironi S, Cazzaniga M, Rossi GP, Bellani G, Pesenti A Is helmet CPAP first line pre-hospital treatment of presumed severe acute pulmonary edema? Intensive Care Med 2009, 35:656-662.

29. Tonnelier JM, Prat G, Nowak E, Goetghebeur D, Renault A, Boles JM, L'her E: Noninvasive continuous positive airway pressure ventilation using a new helmet interface: a case-control prospective pilot study. Intensive Care Med 2003, 29:2077-2080

30. Antonelli M, Conti G, Moro ML, Esquinas A, Gonzalez-Diaz G, Confalonieri M, Pelaia P, Principi T, Gregoretti C, Beltrame F, Pennisi MA, Arcangeli A, Proietti R, Passariello M, Meduri GU: Predictors of failure of noninvasive positive pressure ventilation in patients with acute hypoxemic respiratory failure: a multi-center study. Intensive Care Med 2001, 27:1718-1728.

31. Antonelli M, Conti G, Esquinas A, Montini L, Maggiore SM, Bello G, Rocco M, Maviglia R, Pennisi MA, Gonzalez-Diaz G, Meduri GU: A multiple-center survey on the use in clinical practice of noninvasive ventilation as a firstline intervention for acute respiratory distress syndrome. Crit Care Med 2007, 35:18-25.

32. Antonelli M, Conti G, Pelosi P, Gregoretti C, Pennisi MA, Costa R, Severgnini P, Chiaranda M, Proietti R: New treatment of acute hypoxemic respiratory failure: noninvasive pressure support ventilation delivered by helmet a pilot controlled trial. Crit Care Med 2002, 30:602-608.

33. Constantin JM, Grasso S, Chanques G, Aufort S, Futier E, Sebbane M, Jung B, Gallix B, Bazin JE, Rouby JJ, Jaber S: Lung morphology predicts response to recruitment maneuver in patients with acute respiratory distress syndrome. Crit Care Med 2010, 38:1108-1117

34. Patroniti N, Foti G, Cortinovis B, Maggioni E, Bigatello LM, Cereda M, Pesenti A Sigh improves gas exchange and lung volume in patients with acute respiratory distress syndrome undergoing pressure support ventilation. Anesthesiology 2002, 96:788-794.

35. Pelosi P, Cadringher P, Bottino N, Panigada M, Carrieri F, Riva E, Lissoni A Gattinoni L: Sigh in acute respiratory distress syndrome. Am J Respir Crit
Care Med 1999, 159:872-880

36. Cammarota G, Vaschetto R, Turucz E, Dellapiazza F, Colombo D, Blando C, Della CF, Maggiore SM, Navalesi P: Influence of lung collapse distribution on the physiologic response to recruitment maneuvers during noninvasive continuous positive airway pressure. Intensive Care Med 2011, 37:1095-1102

37. Isgro S, Zanella A, Sala C, Grasselli G, Foti G, Pesenti A, Patroniti N: Continuous flow biphasic positive airway pressure by helmet in patients with acute hypoxic respiratory failure: effect on oxygenation. Intensive Care Med 2010, 36:1688-1694.

38. Cammarota G, Olivieri C, Costa R, Vaschetto R, Colombo D, Turucz E, Longhini F, Della CF, Conti G, Navalesi P: Noninvasive ventilation through a helmet in postextubation hypoxemic patients: physiologic comparison between neurally adjusted ventilatory assist and pressure support ventilation. Intensive Care Med 2011, 37:1943-1950

39. Conti G, Costa R, Antonelli M: Non invasive ventilation in immunocompromised patients. Minerva Anestesio/ 2011, 77:342-348.

40. Hilbert G, Gruson D, Vargas F, Valentino R, Gbikpi-Benissan G, Dupon M, Reiffers J, Cardinaud JP: Noninvasive ventilation in immunosuppressed patients with pulmonary infiltrates, fever, and acute respiratory failure. N Engl J Med 2001, 344:481-487.

41. Principi T, Pantanetti S, Catani F, Elisei D, Gabbanelli V, Pelaia P, Leoni P: Noninvasive continuous positive airway pressure delivered by helmet in hematological malignancy patients with hypoxemic acute respiratory failure. Intensive Care Med 2004, 30:147-150.

42. Rocco M, Dell'Utri D, Morelli A, Spadetta G, Conti G, Antonelli M, Pietropaoli P. Noninvasive ventilation by helmet or face mask in immunocompromised patients: a case-control study. Chest 2004, 126:1508-1515.

43. Rabitsch W, Schellongowski P, Kostler WJ, Stoiser B, Knobl P, Locker GJ, Sperr W, Burgmann H, Herkner H, Keil F, Frass M, Staudinger T: Efficacy and tolerability of non-invasive ventilation delivered via a newly developed helmet in immunosuppressed patients with acute respiratory failure. Wien Klin Wochenschr 2003, 115:590-594

44. The aetiology, management and outcome of severe community-acquired pneumonia on the intensive care unit. The British Thoracic Society Research Committee and The Public Health Laboratory Service. Respir Med 1992, 86:7-13.

45. Carron M, Freo U, Zorzi M, Ori C: Predictors of failure of noninvasive ventilation in patients with severe community-acquired pneumonia. J Crit Care 2010, 25:540-514.

46. Cosentini R, Brambilla AM, Aliberti S, Bignamini A, Nava S, Maffei A, Martinotti $\mathrm{R}$, Tarsia P, Monzani V, Pelosi P: Helmet continuous positive airway pressure vs oxygen therapy to improve oxygenation in community-acquired pneumonia: a randomized, controlled trial. Chest 2010, 138:114-120.

47. Kumar A, Zarychanski R, Pinto R, Cook DJ, Marshall J, Lacroix J, Stelfox T, Bagshaw S, Choong K, Lamontagne F, Turgeon AF, Lapinsky S, Ahern SP, Smith O, Siddiqui F, Jouvet P, Khwaja K, McIntyre L, Menon K, Hutchison J, Hornstein D, Joffe A, Lauzier F, Singh J, Karachi T, Wiebe K, Olafson K, Ramsey C, Sharma S, Dodek P, et al.: Critically ill patients with 2009 influenza $A(H 1 N 1)$ infection in Canada. JAMA 2009, 302:1872-1879.

48. Rello J, Rodriguez A, Ibanez P, Socias L, Cebrian J, Marques A, Guerrero J, Ruiz-Santana S, Marquez E, Nogal-Saez F, Alvarez-Lerma F, Martinez S, Ferrer M, Avellanas M, Granada R, Maravi-Poma E, Albert P, Sierra R, Vidaur L, Ortiz P, Prieto dP, I, Galvan B, Leon-Gil C: Intensive care adult patients with severe respiratory failure caused by Influenza A (H1N1)v in Spain. Crit Care 2009, 13:R148

49. Belenguer-Muncharaz A, Reig-Valero R, Altaba-Tena S, Casero-Roig P, Ferrandiz-Selles A: [Noninvasive mechanical ventilation in severe pneumonia due to H1N1 virus]. Med Intensiva 2011, 35:470-477.

50. Chiumello D, Chevallard G, Gregoretti C: Non-invasive ventilation in postoperative patients: a systematic review. Intensive Care Med 2011 37:918-929

51. Harpole DH Jr, DeCamp MM Jr, Daley J, Hur K Oprian CA, Henderson WG, Khuri SF: Prognostic models of thirty-day mortality and morbidity after major pulmonary resection. J Thorac Cardiovasc Surg 1999, 117:969-979.

52. Wong DH, Weber EC, Schell MJ, Wong AB, Anderson CT, Barker SJ: Factors associated with postoperative pulmonary complications in patients with severe chronic obstructive pulmonary disease. Anesth Analg 1995, 80:276-284.

53. Squadrone V, Coha M, Cerutti E, Schellino MM, Biolino P, Occella P, Belloni G, Vilianis G, Fiore G, Cavallo F, Ranieri VM: Continuous positive airway pressure for treatment of postoperative hypoxemia: a randomized controlled trial. 
JAMA 2005, 293:589-595.

54. Conti G, Cavaliere F, Costa R, Craba A, Catarci S, Festa V, Proietti R, Antonelli M: Noninvasive positive-pressure ventilation with different interfaces in patients with respiratory failure after abdominal surgery: a matchedcontrol study. Respir Care 2007, 52:1463-1471.

55. Redondo Calvo FJ, Madrazo M, Gilsanz F, Una R, Villazala R, Bernal G: Helmet noninvasive mechanical ventilation in patients with acute postoperative respiratory failure. Respir Care 2012, 57:743-752.

56. Barbagallo M, Ortu A, Spadini E, Salvadori A, Ampollini L, Internullo E, Ziegler S, Fanelli G: Prophylactic use of helmet-CPAP after pulmonary lobectomy: a prospective randomized controlled study. Respir Care 2012, 57:1418-1424.

57. Antonelli M, Pennisi MA, Pelosi P, Gregoretti C, Squadrone V, Rocco M, Cecchini L, Chiumello D, Severgnini P, Proietti R, Navalesi P, Conti G:

Noninvasive positive pressure ventilation using a helmet in patients with acute exacerbation of chronic obstructive pulmonary disease: a feasibility study. Anesthesiology 2004, 100:16-24

58. Antonaglia V, Ferluga M, Molino R, Lucangelo U, Peratoner A, Roman-Pognuz E, De Simoni L, Zin WA: Comparison of noninvasive ventilation by sequential use of mask and helmet versus mask in acute exacerbation of chronic obstructive pulmonary disease: a preliminary study. Respiration 2011, 82:148-154.

59. Navalesi P, Costa R, Ceriana P. Carlucci A, Prinianakis G, Antonelli M, Conti G, Nava S: Non-invasive ventilation in chronic obstructive pulmonary disease patients: helmet versus facial mask. Intensive Care Med 2007, 33:74-81

60. Vargas F, Thille A, Lyazidi A, Campo FR, Brochard L: Helmet with specific settings versus facemask for noninvasive ventilation. Crit Care Med 2009, 37:1921-1928.
61. Goldstein RA, Rohatgi PK, Bergofsky EH, Block ER, Daniele RP, Dantzker DR, Davis GS, Hunninghake GW, King TE Jr, Metzger WJ, et al:: Clinical role of bronchoalveolar lavage in adults with pulmonary disease. Am Rev Respir Dis 1990, 142:481-486.

62. Antonelli M, Pennisi MA, Conti G, Bello G, Maggiore SM, Michetti V, Cavaliere F, Proietti R: Fiberoptic bronchoscopy during noninvasive positive pressure ventilation delivered by helmet. Intensive Care Med 2003, 29:126-129.

63. Constantin JM, Schneider E, Cayot-Constantin S, Guerin R, Bannier F, Futier E, Bazin JE: Remifentanil-based sedation to treat noninvasive ventilation failure: a preliminary study. Intensive Care Med 2007, 33:82-87.

64. Hilbert G, Clouzeau B, Nam BH, Vargas F: Sedation during non-invasive ventilation. Minerva Anestesiol 2012, 78:842-846.

65. Rocco M, Conti G, Alessandri E, Morelli A, Spadetta G, Laderchi A, Di Santo C Francavilla S, Pietropaoli P: Rescue treatment for noninvasive ventilation failure due to interface intolerance with remifentanil analgosedation: a pilot study. Intensive Care Med 2010, 36:2060-2065.

doi:10.1186/cc11875

Cite this article as: Esquinas Rodriguez AM, et al: Clinical review: helmet and non-invasive mechanical ventilation in critically ill patients. Critical Care 2013, 17:223. 


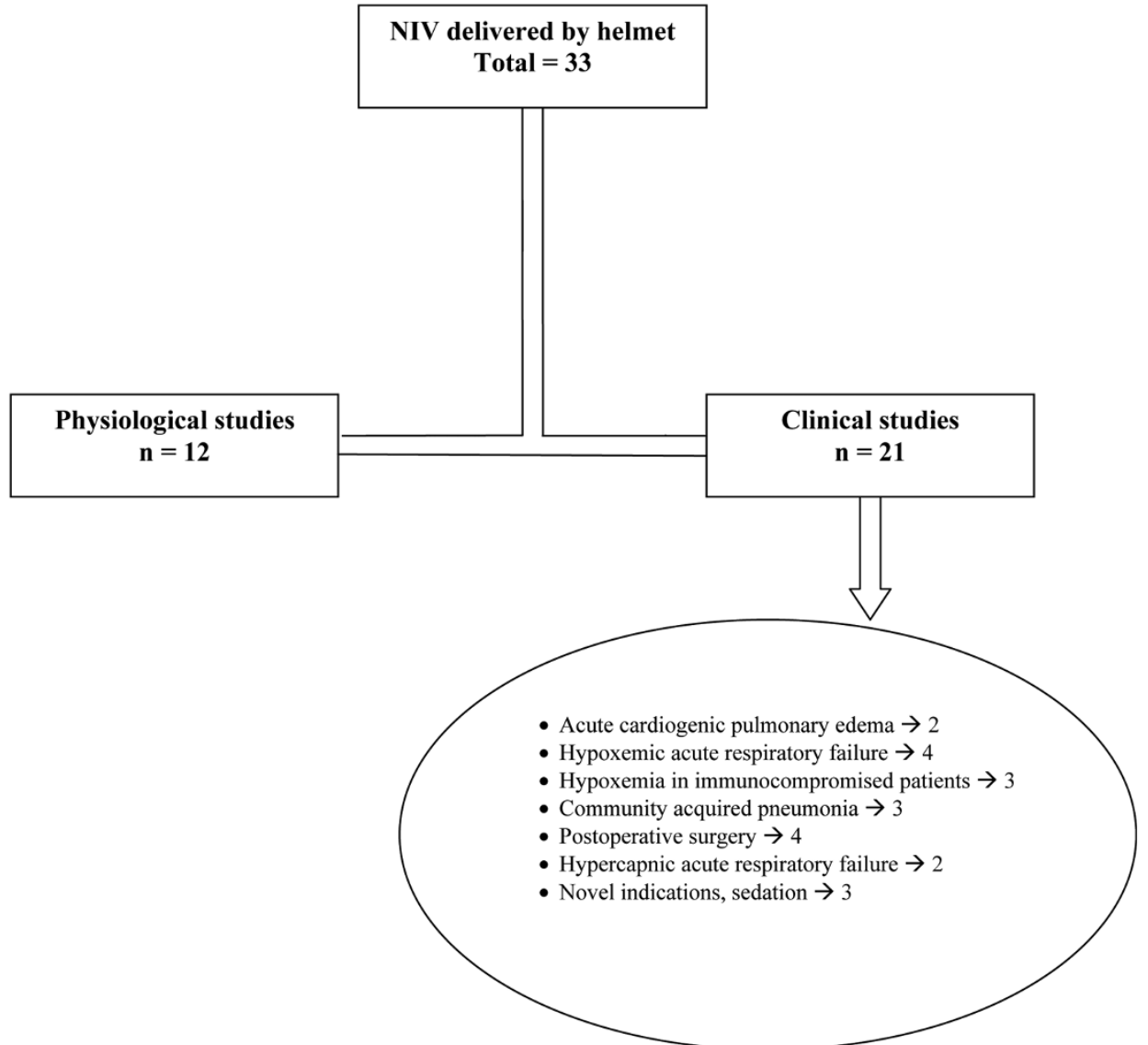

